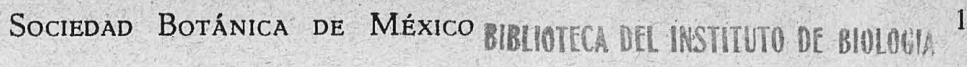

\title{
Exploraciones en el Estado de Hidalgo
}

\author{
Por el Dr. Ladislao PARAY
}

Hace tres años que recorrí la región situada en el limite oriental del Estado de Hidalgo y Norte del de Puebla, y desde entonces decidi volver a explorarla más detenidamente para continuar mis observaciones sobre la flora. Esta vez traté de llegar a esa región por diversas rutas, completando de esa manera mis conocimientos del terreno. El objetivo principal del viaje era llegar al pueblo de San Bartolo Tutotepec, explorar sus alrededores y visitar las grutas que están en la cercanía de la población.

Una mañana del mes de septiembre salí de Agua Blanca en compañia del Prof. Otto Goetze, atravesando unos bosques todavia casi intactos, que se componen sobre todo de coniferas y encinos. Abunda el Cupressus Benthami, que los naturales llaman "sabino"; entre los pinos noto los Pinus teocote, oocarpa, patula, ayacahuite, etc. En esta región el nombre general de los pinos es "ocavetes" en lugar de ocotes. Los encinos abundan y noto distintas especies, que no he determinado todavia. Los indigenas tienen tres nombres distintos para las especies del género Quercus: el encino de hojas chicas se llama "manzanillo"; el de hojas medianas y obscuras, "encino" y el de ho jas grandes y lustrosas y con la bellota grande, "papatlán".

Observo gran cantidad de Clethra, cuyo nombre popular es "pahulla". Esta especie es distinta de la Clethra quercifolia y es probablemente la Clethra Alcoceri. Más abajo encuentro la Clethra macrophylla. Abundan los Alnus, especialmente el Alnus glabrata. La vegetación arbustiva se compone de Arctostaphylos, Senecio sinuatus y Senecio angustifolius, Baccharis. Ardisia y una Ericácea llamada aqui "chahua" (Andromeda ferruginea?), La vegetación herbácea está re- 
presentada principalmente por Castilleja, Salvia y Tibouchina. La Tibouchina Purpusi, que es la más abundante y característica de la región, se encuentra en alturas de más de 200 metros sobre el nivel del mar. Abunda también la Cedronella (toronjil), la cual tiene flores mucho más chicas que la que hay en Valle de México. Los tratados mencionan una sola especie de este país, es decir, la Cedronella mexicana; sin embargo, esta última, tan abundante en el cerro de Chichinautzin, tiene flores de unos tres a cuatro centimetros de largo. En la Sierra de Guadalupe creze una Cedronella con flores de unos dos a tres contímetros de largo y con los verticilos flojos, mientras que la especie del Chichinautzin tiene verticiclos compactos y floribundos. La especie encontrada eil los montes dée Agua Blanca tiene flores de uno a dos centímetros de largo, en verticilos compactos. Por lo demás, las hojas de estas tres Cedronellas son iguales, tanto en forma como en tamaño. Ignoro si se trata de tres cspecies o de tres variedades.

Después de dos horas de cabalgata se llega a una región llamada Cumbre de Muridores, que tiene una altura de 2400 metros sobre el nivel del mar. Este punto es la entrada de la sierra, y desde alli se obtiene una vista maravillosa de la región oriental del Estado de $\mathrm{Hi}$ dalgo y del Oeste del de Veracruz. Por todas partes se ven enormes montañas casi verticales, cañadas y barrancas angostas, y ríos serpenteando en el fondo de valles profundos; algo como un mar de montañas, un laberinto de cañones y precipicios. A medida que iniciamos el descenso, la vegetación cambia totalmente: aparecen los interesantes árboles que la Botánica llama Weinmannia pinnata y el vul go "garrapatito". Las Weinmannias, que son tan abundantes en Colombia, en México crecen en la vertiente oriental de la Sierra Madre y caracterizan la vegetación de las montañas de los Estados de Veracruz, Hidalgo y Oaxaca, y florecen precisamente en esta época. Aun que sus flores son inconspicuas y presentan un espectáculo pintoresco con sus hojas lustrosas y sus flores dispuestas en largas espigas. Las Weinmannias indican que nos encontramos en la región húmeda semitropical.

Los encinos dominan todavia el paisaje y hay Pinus y Älnus. Estos últimos bajan a niveles mucho menores, pues se ven a los 100 metros. Crece aqui un arbusto del porte de la Fuchsia microphylla, pero con las flores completamente blancas, y una Salvia arbustiva con las flores de intenso color azul obscuro: las Melastomatáceas predo- 
minan, por ejemplo la Miconia mexicana: las Ternstroemias se hacen notar por sus hojas lustrosas y sus frutos de un color rojo vivo. En esta región les dan el nombre de "palo agrio" o "ixquefé".

Después de bajar por una vereda que por lo empinado parece más bien una escalera se llega a un punto llamado Cueva Ahumada, y a continuación se baja aun más por angostas y tortuosas sendas. Llaman la atención las laderas inclinadas y sembradas de maíz. No escapan al cultivo ni las pendientes más pronunciadas. Al mismo tiempo que se admira el trabajo del hombre en esos lugares, se ve con tristeza la destrución de los hermosos bosques que antes cubrian estos cerros, y piensa uno que pronto se agotarán esas tierras y sobre todo, no es-

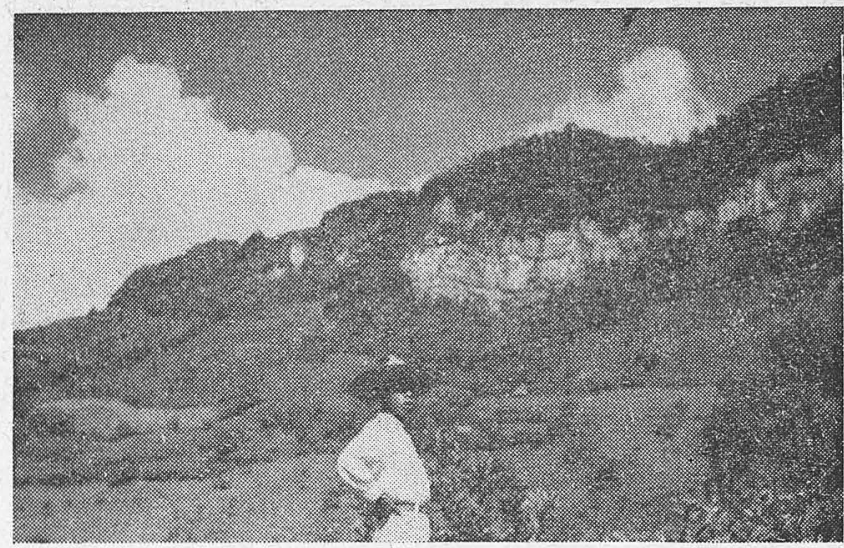

Muralla de la gruta

caparán al efecto de la erosión que forzosamente tienen que arruinarlas. El botánico ya no encuentra mucho de la vegetación original y es necesario ascender a los lugares más escarpados o bajar al fondo de las barrancas para obtener algo interesante.

Afortunadamente, cerca del pueblo de San Bartolo todavía hay bastantes bosques, sobre todo en los alrededores de la gruta. Su situación es sumamente pintoresca y no hay duda de que cuando llegue a estos lugares la carretera, será una atracción turística. Es un pueblo limpio y sus habitantes son afables y hospitalarios. Los señores José Islas y Fernando Ponce son grandes amigos de los excursionistas y les facilitan la estancia en el pueblo. 


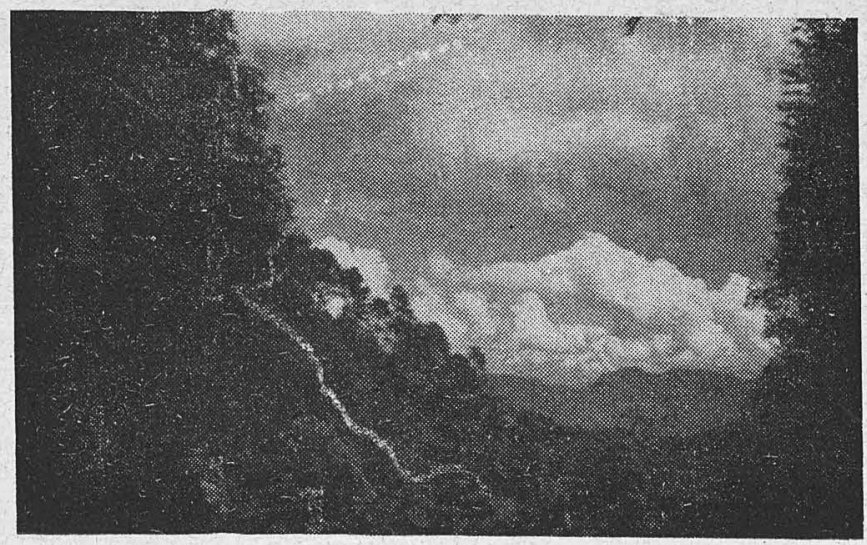

Paisaje de San Bartolo

La atracción principal es la famosa gruta, que se encuentra casi en la cumbre de una gran montaña en cuya falda está el pueblo. Di cha montaña está coronada por una larga muralla de rocas imponentes. Hay que subir unos 600 metros sobre el nivel de la población, y apenas al salir se ven gigantescos y frondosos árboles de Platanus mexicana, cuyo nombre local es "álamo" o "guayabillo", y fresnos, que aqui se llama "Detatillos", hay enorme cantidad de Gilibertia, cuyo nombre es "palo de agua". Los "colorines" (Erythrina) se llaman "quemites" o "quimites"; la sensitiva (Mimosa pudica) se denomina "dormilona". Tenemos un guía inteligente, una especie de botánico indigena que nos enseña todos los nombres populares.

Antes de llegar al pie de la enorme muralla tenemos que atravesar unos bosques tupidos donde hay que abrir brecha a machetazos. Están caracterizados por gran cantidad de Croton draco, llamado popularmente "grado". En ninguna parte he observado tan enorme cantidad de esta especie arbórea como aquí. Abundan las plantas urticantes como Urera urens, Urera caracasana, Urtica, Cnidoscolus y $U_{t}$ ticastrum mexicanum, plantas temibles que apenas toleran cerca otras especies vegetales, y abundan tanto estas plantas malignas, que es imposible pasar entre ellas sin recibir quemaduras, quedando los brazos y la cara llenos de innumerables piquetes y excoriaciones durante varios dias. El suelo está tapizado de fantásticas ortigas, todas en flor y tan bonitas, que parecen las plantas más inocentes del mundo. Por fin, después de una heróica lucha de más de una hora contra esos crue- 
les vegetales, llegamos al pie de la gigantesca muralla, que mide varios kilómetros de largo y como unos 200 mits. de altura. Ante nuestros ojos atónitos apareció la abertura de la majestuosa gruta. Sus fauces son imponentes, por lo menos como las de las Grutas de Cacahuamilpa, pero el interior es más interesante. Lo más curioso es que la vegjetación penetra hasta unos 50 metros de distancia desde la abertura. El primer salón mide unos 200 metros de largo por unos 50 de alto y tiene en medio un lago llamado de la Virgen,debido a una estalactira que afecta forma femenina. A los lados se ven otras estalactitas y estalagmitas y una pequeña cascaria que alimenta el lago.

Es interesante la vegetación cavernicola. El piso está cubierto de una humilde e insignificante Begonia con flores amarillento-verdosas. Anoto las siguientes plantas: en la entrada hay Bouvardid, Tecoma y un árbol llamado "bola de tejón", que es la Trichilia havanensis. Más al interior hay una Urera caracasana, Buddleia, Bocconia, Begonia, Miconia y Trema micrantha. Algunas plantas arbustivas cuelgan del techo, pero están tan altas, que es imposible alcanzarlas.

Después de recorrer el primer salón entramos al segundo, que es un poco menor que el primero. Penetramos por último, al tercero, desde donde comienza un estrecho agujero que conduce hacia las misteriosas entrañas de la tierra.

Al salir de la gruta exploro la vegetación de la base de la mura1la: abunda el precioso Achimenes grandiflora, de color violáceo y de flores enormes, que crece también en otras partes de los alrededo-

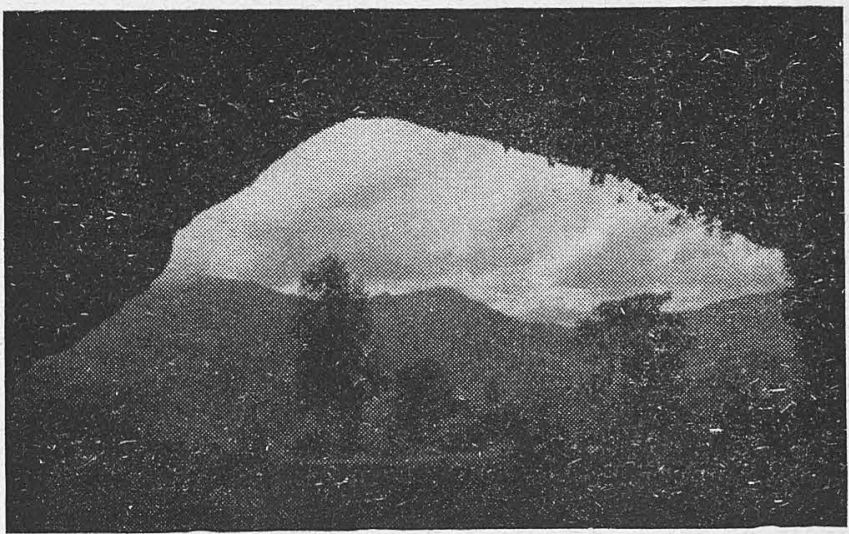

Entrada de la Gruta 
res. Hay otro Achimenes todavía más vistoso que el anterior, con hermosas corolas azules de unos 3 a $4 \mathrm{~cm}$. de largo y hojas de $10 \mathrm{~cm}$.; es sumamente ornamental y sería el orgullo de cualquier jardín. Es curioso que hay pocos ejemplares y no crece en los lugares vecinos. Más tarde vi otras dos especies de Achimenes que por no haberlas colectado luego, me privé de ellas, pues no aparecieron más.

Otro dia exploramos los bosques cercanos al río de San Bartolo, que corre en una cañada angosta y profunda. Abundan las Perseas, llamadas "pahuas" y los nogales (Hicoria pecan); el amate (Ficus) se llama aqui "xalame"; vi gran cantidad de Equisetum y de Hamelia. llamada "tres hojitas". Hay árboles de Saurauia, que llaman "acalama". Grandes Ruellias de flores azules adornan los prados. Se ven el Croton draco, Platanus mexicana, Chiococca, Maranta arundinacea y Trema micrantha.

Dedicamos otro día a explorar otros cerros que se encuentran en el camino a Huehuetla. El más grande se llama el Cerro de la Campana, donde abundan Pinus, Quercus, Clethra, Pachyrhizus, Begonias, Coccocypselum, Heterocentron, Kohleria, Ascyrum, Ardisia, Vernonia arctioides, y gran cantidad de Melastomatáceas, como Miconia. Leandra y Tibouchina. Entre las epifitas noto sobre los encinos numerosas orquídeas, en su mayoria del género Epidendrum, pero hay también Maxillaria, Stanhopea y Cattleya. Vi también la Columnea Schiedeana, la Cobaea scandens y un Senecio trepador. De regreso descubro cerca de las casas una cactácea del género Pereskia, con flores rosadas. Hay Ipomoeas de todos los colores y tamaños y esa vegetación exuberante está salpicada de millones de mariposas multicolores, tan confiadas, que pueden capturarse con la mano. De esa manera primitiva pude adquirir una envidiable colección de las más raras y brillantes.

Después de cinco días de estancia en ese lugar paradisíaco, salimos de San Bartolo Tutotepec rumbo a la estación de Honey, pasando por el pueblo de Tenango de Doria. Caminamos a un lado del enor me Cerro de los Brujos, debajo de gigantescas rocas, que ofrecen un paisaje subyugador. Los peñascos más fantásticos se levantan encima de nosotros, mientras se abren abajo vertiginosos abismos. En el bosque, entre Quercus y Ericaceas, crece el curioso Chiloranthemum trifidum y una Acantácea, probablemente Beloperone, con vistosas flores rojas. Nos saludan las últimas Weinmannias y Ternstroemias. 
La bajada del Cerro de Los Brujos es una de las más pintorescas que he visto. Al frente se ve una larga y elevada montaña, de unos $7 \mathrm{Km}$. de largo y 1500 metros de alto desde su base. Sus crestas están coronadas por rocas de formas fantásticas, rodeadas de bosques tenebrosos.

Pasamos por los poblados de Chila y Santa Mónica, en continuo subir y bajar por empinadas laderas. En una roca que parece colgante en el aire noto un hermoso arbusto de flores amarillas, y después de una lucha titánica para adquirir una ramilla, encuentro que es un Labium de singular belleza.

Poco a poco llegamos a los bosques de Coniferas, a 2000 metros sobre el nivel del mar, y después de 10 horas de cabalgata bajo una lluvia pertinaz, llegamos a la Estación de Honey, donde nos espera el tren que nos conduce a la Capital. 